\title{
A DIFUSÃO HISTÓRIOGRAFICA DA EDUCAÇÃO EM SANTA CATARINA: INTERFACES COM O REGIONAL E COM O NACIONAL
}

\author{
Maria Teresa Santos Cunha ${ }^{1}$ \\ Tania Cordova²
}

\section{RESUMO}

O trabalho apresenta um estudo da produção em História da Educação em Santa Catarina com base no que foi publicado em eventos científicos de caráter regional e nacional, entre os anos de 2000 e 2011 . O objetivo é compreender as formas pelas quais se tece o entendimento sobre a escrita da história da educação no estado. Os eventos cotejados foram: os Congressos da SBHE, as Reuniões da ANPED e as reuniões da ANPED Sul. Mapear a produção historiográfica da educação catarinense, circunscrita aos trabalhos publicados nestes eventos, auxiliou na percepção desta historiografia nas injunções das leis de um lugar, de uma prática de pesquisa e de uma escrita constituídas institucional e historicamente e apropriado pelos sujeitos-pesquisadores.

PALAVRAS-CHAVE: Cartografia, História da Educação em Santa Catarina; Produção historiográfica.

\section{THE HISTORIOGRAPHICAL DISSEMINATION OF EDUCATION IN SANTA CATARINA: INTERFACES WITH THE REGIONAL AND THE NATIONAL}

\begin{abstract}
The paper presents a study of the production in the History of Education in Santa Catarina based on what was published in scientific events of regional and national character, between the years 2000 and 2011. The objective is to understand the forms through which weaves understanding about writing the history of education in the state. The collated events were: the Congress of SBHE, the Meeting of ANPED and meetings of ANPED South Map the historiography of Santa Catarina education confined to the papers published in these events, helped in perception of this historiography in the injunctions of the laws of a place, of a practical research and a written and historically established institutional and individuals-appropriate by researchers.
\end{abstract}

KEY WORDS: Cartography, History of Education in Santa Catarina; Historiographical Production.

\section{INTRODUÇÃO}

Não pretendo sugerir que este processo algum dia venha a terminar; a paisagem do passado está distante demais, é demasiado obscura ou, na história moderna, excessivamente apinhada para que tenha fim. Na verdade, uma tal interpretação definitiva - o mapa que nunca precisará de revisões - é irrealizável por princípio. Um modo corriqueiro de formular este princípio é dizer que cada geração deve reescrever as histórias das gerações anteriores. Esse lugar-comum é verdadeiro, mas não pela razão geralmente apresentada. É verdadeiro, antes, por terem os acontecimentos uma posteridade que pode prosseguir até o final dos tempos - ou, quando menos, até o final da historiografia (GAY, 1990, p. 191).

Ao esquadrinhar, com mapas e trilhas, o caminho delineado pela pesquisa em História da Educação em Santa Catarina toma-se como referência as proposições organizadas no trabalho "Uma

\footnotetext{
1 Professora Doutora do Departamento de História e dos Programas de Pós-graduação em História e em Educação da Universidade do Estado de Santa Catarina - UDESC. mariatsc@gmail.com

2 Doutoranda do Programa de Pós-Graduação da Universidade do Estado de Santa Catarina - UDESC. taniacordova@bol.com.br
} 
Cartografia da Pesquisa em História da Educação na Região Sul: Paraná, Santa Catarina e Rio Grande do Sul (1980 - 2000)"3, trabalho esse, que configura o primeiro levantamento da produção científica no campo da pesquisa historiográfica da Educação no sul do país.

Tomar o estudo citado, como ponto de partida para a construção desta escrita não significa operar com a reprodução da obra, mas, como propõe o historiador Peter Gay, na epígrafe que abre este texto, é compreender que "a história, em suma, é inacabada no sentido de que o futuro sempre utiliza seu passado de novas maneiras" (1990, p. 191), exigindo do pesquisador em História da Educação, um repensar, um (re)mapear a produção historiográfica da educação em Santa Catarina.

Nesta perspectiva, o objetivo do texto parte da organização do levantamento da produção científica em História da Educação Catarinense realizado entre os anos de 2000 a 2011 a partir das categorias de análise organizadas pelo primeiro trabalho que se dedicou a este intento no período entre 1980 a 2000. O caminho percorrido na busca de indícios das escritas historiográficas da educação no estado de Santa Catarina leva aos espaços privilegiados de visibilidade, socialização e debates acerca da investigação em História da Educação - os eventos científicos.

Para além de espaços de visibilidade, os eventos científicos são, ainda, espaços fomentadores de aproximações cosmopolitas, uma vez que tem propiciado ao campo da História da Educação uma intensa interação, um intercâmbio teórico entre pesquisadores brasileiros e pesquisadores de outros países $^{4}$. O que se apresenta como uma possibilidade à reconfiguração do campo historiográfico e promove a ampliação do mesmo, na proporção que ultrapassa os limites do regional e do nacional ao incorporarem trabalhos de pesquisadores internacionais.

O balanço cartográfico, da pesquisa, organizado no período entre 1980 a 2000 em Santa Catarina, por opção metodológica, não abrangeu os eventos científicos locais e nacionais e buscou em outros espaços como livros publicados, dissertações e relatórios de pesquisa, indícios da produção em história da educação no estado ${ }^{5}$. Para esta investigação, esta opção metodológica não é possível ser mantida haja vista a significativa ampliação e projeção da pesquisa na área de História da Educação catarinense nos últimos anos. Todavia, destaca-se que a dificuldade encontrada em acessar os resumos e artigos publicados em anais de eventos na forma eletrônica configurou, também, uma opção

\footnotetext{
${ }^{3}$ Este trabalho foi organizado pelos pesquisadores: Maria Helena Camara Bastos, Marcus Levy Albino Bencosta e Maria Teresa Santos Cunha; que apresentam as primeiras discussões acerca da ampliação significativa dos espaços de produção em História da Educação na região Sul, como também alicerça um mapeamento significativo das produções da pesquisa historiográfica no período entre 1980 a 2000.

4 Ao observar os Congressos da Sociedade Brasileira de História da Educação - CBHE é possível destacar e reforçar a circulação do pensamento historiográfico internacional. Um exemplo disso são as edições dos Congressos desta sociedade que desde 2000 vem trazendo pesquisadores de outros países para proferir as Conferências de Abertura dos trabalhos do evento. Em 2000, a primeira edição do Congresso contou com a presença do pesquisador espanhol Antonio Viñao Frago; em 2002, a Conferência de abertura foi conduzida pela pesquisadora francesa Anne-Marie Chartier; em 2004, a terceira edição teve como conferencista o pesquisador Anton Costa Rico; em 2006, a Conferência de abertura foi conduzida pela pesquisadora Elise Rockwell; a quinta edição em 2008 trouxe o conferencista espanhol Manuel Ferraz Lorenzo e em 2010 a conferência foi conduzida pelo francês Jean Hébrard.

5 Informação retirada do Quadro 4 - A natureza da produção do conhecimento em História da Educação na Região Sul (1980 - 2000). In: BASTOS, M.H.C; BENCOSTTA, M.L.A; CUNHA, M. T. S. Uma Cartografia da Pesquisa em História da Educação na Região Sul: Paraná, Santa Catarina e Rio Grande do Sul (1980 - 2000). Pelotas: Seiva, 2004, p. 27.
} 
metodológica que não contemplou todos os eventos de repercussão nesta área de pesquisa. Sendo necessário reorganizar o olhar para os eventos científicos deste campo de pesquisa ${ }^{6}$.

O mapeamento da pesquisa em História da Educação em Santa Catarina, realizado nesta investigação, destaca a presença da produção científica em três eventos de abrangência regional e nacional. Em âmbito nacional destacam-se as Reuniões Anuais organizadas pela Associação Nacional da Pós-Graduação em Pesquisa e Educação (ANPED) e as Edições dos Congressos da Sociedade Brasileira de História da Educação (SBHE), no que tange a abrangência regional, o levantamento contempla as reuniões bianuais da ANPED Sul.

O procedimento de localização da produção em História da Educação nestes eventos científicos opera com o jogo de escalas, na expressão de Jacques Revel (1992), lançando mão de diferentes graus de visão como forma de aproximar o real na escrita da história da educação catarinense. Neste jogo de escalas, o olhar desloca-se para o regional, reduzindo a escala para em seguida ampliá-la e observar a historiografia da educação catarinense em âmbito nacional.

$\mathrm{Na}$ organização do texto, o primeiro movimento busca identificar os pesquisadores catarinenses em seu lócus de produção. Para isso, o olhar converge para as reuniões bianuais da ANPED Sul. Nessa perspectiva, a lente que perscruta os temas, os períodos e as categorias de construção do campo historiográfico educacional recaiu sobre o fazer historiográfico dos pesquisadores catarinenses buscando apropriar-se das maneiras pelas quais estes, vêm construindo a escrita da História da Educação.

No segundo movimento, amplia-se a lente e se busca trilhar os caminhos percorridos pelos pesquisadores catarinenses nos eventos nacionais. O olhar espreita a produção histórica educacional apresentada nas Reuniões anuais da ANPED Nacional e nos Congressos promovidos pela Sociedade Brasileira de História da Educação (CBHE), onde o foco da lente firma-se, também, nas temáticas, períodos de interesse à pesquisa histórico educacional.

Começamos a trilhar o primeiro itinerário...

\section{OS SEMINÁRIOS DA ANPED SUL}

Vinculado a ANPED Nacional, o Seminário de Pesquisa em Educação da Região Sul - ANPED Sul é um evento referência na difusão de pesquisas desenvolvidas por discentes e docentes nos Programas de Pós-Graduação e por pesquisadores da área da educação. O primeiro Seminário da ANPED Sul aconteceu em 1998, na Universidade Federal de Santa Catarina e afirmou- se como um importante espaço de circulação para os pesquisadores da educação no estado catarinense e nos dois outros estados que compõem a região sul do país. No período entre 2000 e 2011, foram realizados seis Seminários, nos quais foram identificadas as produções científicas que se aproximam do conhecimento em História da Educação. A incidência desta produção, por edição do Seminário da ANPED Sul, pode ser vislumbrada no quadro abaixo:

6 Destaca-se a dificuldade em acessar os anais dos Congressos da Associação Sul Rio-Grandense de pesquisadores em História da Educação - ASPHE, considerada neste trabalho como um importante espaço de socialização da pesquisa em história da educação. 
Quadro 1 - Apresenta a distribuição dos trabalhos apresentados na ANPED Sul no período entre 2000 a 2010.

\begin{tabular}{|c|c|c|c|}
$\begin{array}{c}\text { Edição do } \\
\text { Seminário da } \\
\text { ANPED Sul }\end{array}$ & $\begin{array}{c}\text { Local sede do } \\
\text { Seminário }\end{array}$ & $\begin{array}{c}\text { Número de trabalhos } \\
\text { de pesquisadores } \\
\text { catarinenses } \\
\text { vinculados a história } \\
\text { da educação }\end{array}$ & TEMAS DO SEMINÁRIO \\
\hline III/2000 & UFRGS/ & 3 & Na contra corrente da Universidade Operacional \\
\hline IV/2002 & UFSC/SC & 15 & Pesquisa em Educação e Compromisso Social \\
\hline V/2004 & PUC/PR & 10 & Pesquisa em Educação: Novas Questões? \\
\hline VI/2006 & UFSM/RS & 3 & Pesquisa em Educação e Inserção Social \\
\hline VII/2008 & UNIVALI/SC & 18 & Formação, Ética e Políticas: Qual Pesquisa? \\
Qual Educação?
\end{tabular}

Fonte: Organizado pelas autoras.

Um dado a ressaltar neste levantamento, é o fato de que deste universo de 59 trabalhos apresentados na APED Sul entre 2000 e 2010, vinte e um (21) estão inseridos no eixo temático História da Educação, sendo que treze (13) foram apresentados em 2008, e oito (8) em 2010. Os outros trinta e oito (38) trabalhos estão alocados em eixos temáticos como: Formação de professores (20); educação, Cidadania e Intercultura (5), Educação, História e Filosofia (5), entre outros eixos que possibilitam tecer aproximações com o campo historiográfico da educação.

Diante desse quadro destaca-se que a inserção do eixo temático História da Educação somente foi inserido na Edição do Seminário em 2008, o que pode estar associado com a implantação e ampliação dos Cursos de Pós-Graduação em Educação no Estado 7 .Este panorama compõe as primeiras evidências da produção do conhecimento em História da Educação presentes nos referidos eventos científico. O levantamento e estudo dos trabalhos esbarraram na ausência de indicadores que poderiam subsidiar os dados sobre a produção da área, uma vez que as palavras-chave (principal descritor utilizado no levantamento), nem sempre estava vinculado ao termo História da Educação. Diante desta ausência, a opção metodológica definiu-se por ancorar a análise nas palavras-chaves por aproximação e aglutinação aos assuntos e temas pertinentes a História da Educação.

O cotejamento por aproximação à História da Educação foi mediado pela instituição de temas que possibilitaram delinear o cenário da pesquisa catarinense, e que resultou na elaboração do quadro quantitativo apresentado a partir dos temas examinados nas seis edições da ANPED Sul visualizados no quadro 2.

\footnotetext{
7 As reflexões acerca da ampliação dos Cursos de Pós-Graduação que contemplam a linha de pesquisa em História e Historiografia da Educação ou ainda, que se aproximam de reflexões, pesquisas nesta área serão tratadas em outros textos que integram a pesquisa sobre a Cartografia da Pesquisa em História da Educação em Santa Catarina.
} 
Quadro 2 - Temas examinados nas edições da ANPED Sul entre os anos de 2000 a 2010

\begin{tabular}{|c|c|c|}
\hline QUANTIDADE & $\%$ & TEMAS EXAMINADOS NAS EDIÇŌES DA ANPED SUL ${ }^{8}$ \\
\hline 21 & 35,5 & HISTÓRIA DA PROFISSÃO DOCENTE E FORMAÇÃO DE PROFESSORES \\
\hline 13 & 22 & POLIITICAS PÚBLICAS E EDUCACIONAIS \\
\hline 12 & 20,3 & EDUCAÇÃO \\
\hline 11 & 18,6 & HISTÓRIA DAS INSTITUIÇÕES DO ENSINO SECUNDÁRIO \\
\hline 9 & 15,2 & HISTORIOGRAFIA E HISTÓRIA DA EDUCAÇÃO BRASILEIRA \\
\hline 8 & 13,5 & DISCIPLINARIZAÇÃO/MECANISMOS DE PODER \\
\hline 8 & 13,5 & PATRIMÓNIO ESCOLAR/CULTURA MATERIAL ESCOLAR \\
\hline 6 & 10 & CULTURA ESCOLAR \\
\hline 6 & 10 & ESTADO/REGIŌES/LOCALIDADE \\
\hline 6 & 10 & HISTÓRIA DAS INSTITUIÇŌES DO ENSINO PRIMÁRIO \\
\hline 6 & 10 & INSTRUÇÃO PÚBLICA \\
\hline 6 & 10 & NACIONALIZAÇÃO \\
\hline 6 & 10 & HISTÓRIA DA LEITURA E DA ESCRITA \\
\hline 5 & 8,5 & EDUCAÇÃO E RELIGIÃO \\
\hline 5 & 8,5 & HISTÓRIA E INFÂNCIAS \\
\hline 5 & 8,5 & INTELECTUAIS/PERSONAGENS HISTÓRICOS \\
\hline 4 & 6,8 & HISTÓRIA E PRÁTICAS DO ENSINO SUPERIOR \\
\hline 4 & 6,8 & PESQUISA \\
\hline 3 & 5,0 & ESCOLAS \\
\hline 3 & 5,0 & HISTÓRIA E POLÍTICAS \\
\hline 3 & 5,0 & IDENTIDADES ÉTNICAS \\
\hline 3 & 5,0 & MODERNIZAÇÃO/MODERNIDADE \\
\hline 3 & 5,0 & REFORMA EDUCACIONAL \\
\hline 2 & 3,4 & AUTOBIOGRAFIA E MEMORIAS \\
\hline 2 & 3,4 & DISCIPLINAS FRONTEIRIÇAS \\
\hline 2 & 3,4 & FONTES E MÉTODOS \\
\hline 1 & 1,7 & EDUCAÇÃO PROFISSIONAL \\
\hline 1 & 1,7 & ESTUDOS CULTURAIS \\
\hline 1 & 1,7 & ESTUDOS DE GÉNERO \\
\hline 1 & 1,7 & PEDAGOGIA \\
\hline
\end{tabular}

Fonte: Organizado pelas autoras.

Ao examinar os temas apresentados nos seis Seminários da ANPED Sul o primeiro movimento da lente se volta para o interesse dos pesquisadores catarinenses. O tema História da Profissão docente e formação de professores configura a temática de maior investimento no campo historiográfico representando $35,5 \%$ (21) do total dos trabalhos. O segundo tema de maior investimento foi o que dimensiona as Políticas Públicas e Educacionais 22\% (13). Estas duas temáticas são seguidas pelos temas Educação 20,3\% (12); História das Instituições do Ensino Secundário 18,6\% (11); Patrimônio escola/cultura material escolar 22\% (13); Disciplinarização/mecanismo de poder 13,5\% (8).

A temática História e Historiografia da Educação brasileira contabiliza 9 aparições (15,2\%) nos trabalhos apresentados nestes Seminários. Situação semelhante ocorre com o tema Cultura Escolar, tema este, fortemente marcado, no campo da História da Educação Brasileira, pela interlocução com a vertente francesa da então chamada Nova História Cultural. Nas seis edições dos Seminários da ANPED Sul, este tema aparece em apenas 6 dos trabalhos apresentados (10\%).

Os dados temáticos referentes a estes eventos científicos demonstram que, no período entre 2000 e 2011, as duas temáticas de maior interesse entre os pesquisadores catarinenses convivem com uma inclinação para outras temáticas. No que se refere aos recortes temporais analisados nos Seminários da ANPED Sul, observa-se que o percurso trilhado pelo campo da pesquisa em História da

${ }^{8} \mathrm{O}$ número da quantidade e da porcentagem diferenciam do total por entrecruzar dois termos para uma mesma publicação. 
Educação em Santa Catarina, entre 2000 e 2011, apresenta uma concentração em três períodos da história política do país que abrangem o final do século XIX até o início da segunda metade do século $X X$.

Dos 59 trabalhos apresentados nos Seminários da ANPED Sul, 38 trabalhos são recortados pelos marcos temporais que correspondem às periodizações denominadas de Primeira República, Estado Novo e Redemocratização. Tal tendência, todavia não faz com que parte do século XIX e a segunda metade do século XX deixem de ser fonte de interesse dos pesquisadores catarinenses, pelo contrário, as tendências acima aludidas coexistem com outros interesses temporais e que podem ser visualizados no quadro 3 , que organiza as demarcações temporais presentes nos trabalhos apresentados.

Quadro 3 - Períodos Pesquisados nos trabalhos apresentados nas seis edições da ANPED Sul

\begin{tabular}{|lcc|}
\hline PERÍODOS PESQUISADOS NOS TRABALHOS DA ANPED SUL & QUANTIDADE & $\%$ \\
\hline IMPÉRIO (1822 - 1889) & $\mathbf{8}$ & $\mathbf{1 3 , 6}$ \\
\hline PRIMEIRA REPÚBLICA (1889-1930) & 16 & $\mathbf{2 7 , 1}$ \\
\hline ESTADO NOVO (1930-1945) & $\mathbf{1 3}$ & $\mathbf{2 2}$ \\
\hline REDEMOCRATIZAÇÃO (1945 - 1964) & $\mathbf{9}$ & $\mathbf{1 5 , 2}$ \\
\hline DITADURA CIVIL MILITAR (1964-1985) & $\mathbf{7}$ & 12 \\
\hline TEMPO PRESENTE (1985 - 2013) & $\mathbf{4}$ & $\mathbf{6 , 8}$ \\
\hline SEM IDENTIFICAÇÃO & $\mathbf{2}$ & $\mathbf{3 , 3}$ \\
\hline
\end{tabular}

Fonte: Organizado pelas autoras.

Perscrutados os vestígios deixados pelos pesquisadores catarinenses da História da Educação nos eventos regionais, o itinerário passa a perseguir outras trilhas.

\section{AS REUNIÕES ANUAIS DA ANPED NACIONAL}

Entre os anos de 2000 e 2011, os pesquisadores catarinenses encaminharam para o circuito Nacional 110 trabalhos científicos caracterizados como pertinentes à História da Educação. Deste número, 22 trabalhos foram apresentados nas Reuniões Anuais da ANPED Nacional. Criada em 1978, sob a premissa de disseminar a pesquisa desenvolvida nos Programas de Pós-Graduação em Educação, a ANPED configura um espaço privilegiado para a discussão, registro e divulgação do conhecimento científico produzido na área de Educação bem como um local de circulação de pesquisadores e estudiosos nas diferentes áreas da Educação.

A quantificação dos trabalhos apresentados nas 12 Reuniões da ANPED, dispostos no quadro abaixo, possibilita problematizar a presença dos pesquisadores catarinenses nestes eventos. Se comparada ao número de trabalhos propostos para os Seminários da ANPED Sul, no mesmo período. A presença da pesquisa catarinense de cunho historiográfico pode ser considerada como pouco expansiva e de pouca projeção no cenário nacional.

Quadro 4 - Apresenta a distribuição dos trabalhos apresentados na ANPED Nacional no período entre 2000 a 2011.

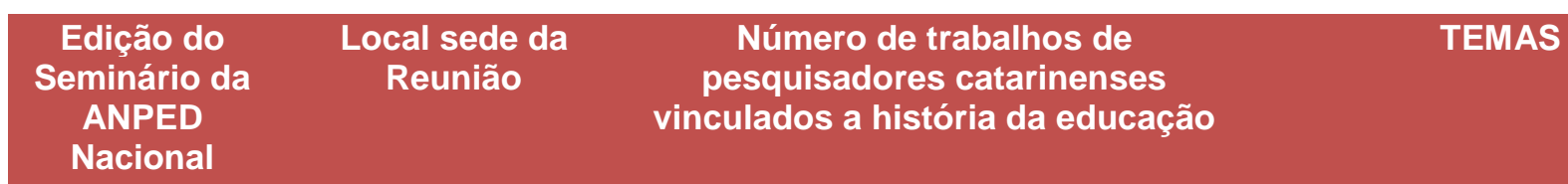




\begin{tabular}{|c|c|c|c|}
\hline $23^{a} / 2000$ & Caxambu/MG & 2 & Não localizado \\
\hline $24 \frac{a}{2} 2001$ & Caxambu/MG & 3 & Não localizado \\
\hline $25 \div / 2002$ & Caxambu/MG & 5 & Não localizado \\
\hline $26^{a} / 2003$ & $\begin{array}{l}\text { Poços de } \\
\text { Caldas/MG }\end{array}$ & 1 & $\begin{array}{c}\text { Novo Governo. Novas } \\
\text { Políticas? }\end{array}$ \\
\hline $27^{a} / 2004$ & Caxambu/MG & 3 & Não localizado \\
\hline $28^{a} / 2005$ & Caxambu/MG & 1 & Não localizado \\
\hline $29 a / 2006$ & Caxambu/MG & 1 & $\begin{array}{c}\text { EDUCAÇÃO, CULTURA E } \\
\text { CONHECIMENTO NA } \\
\text { CONTEMPORANEIDADE: } \\
\text { Desafios e Compromissos }\end{array}$ \\
\hline $30^{a} / 2007$ & Caxambu/MG & 1 & $\begin{array}{l}\text { ANPED: } 30 \text { anos de pesquisa } \\
\text { e compromisso social }\end{array}$ \\
\hline $31^{\mathrm{a} / 2008}$ & Caxambu/MG & 0 & $\begin{array}{c}\text { Constituição Brasileira, } \\
\text { Direitos Humanos e } \\
\text { Educação }\end{array}$ \\
\hline $32^{a} / 2009$ & Caxambu/MG & 3 & $\begin{array}{l}\text { Sociedade, cultura e } \\
\text { educação: novas } \\
\text { regulações? }\end{array}$ \\
\hline $33^{a} / 2010$ & Caxambu/MG & 1 & $\begin{array}{l}\text { Educação no Brasil: } 0 \\
\text { Balanço de uma Década }\end{array}$ \\
\hline $34^{\mathrm{a}} / 2011$ & Natal/RN & 1 & Educação e Justiça Social \\
\hline Total & & 22 & \\
\hline
\end{tabular}

Fonte: Organizado pelas autoras.

A produção científica em História da Educação adentra a ANPED Nacional pelo viés do GT História da Educação ${ }^{9}$, criado em 1984. No período de abrangência deste levantamento foram identificadas 16 produções vinculadas a este GT. Todavia, tal tendência não configura uma regra uma vez que foram identificados trabalhos com conotação histórico educacional em outros GTs como nos grupos que pesquisam os Movimentos Sociais e Educação (2); Educação da criança de 0 a 6 anos (1); Didática (1); Sociologia da Educação (1); Currículo (1). É importante destacar que estes trabalhos compõem o número de produções analisadas neste levantamento.

O quadro a seguir permite visualizar a distribuição dos trabalhos científicos de acordo com os temas de interesse dos pesquisadores em História da Educação em Santa Catarina. Chama a atenção à permanência do tema História da Profissão Docente e Formação de Professores como temática de maior recorrência e visibilidade nestes eventos. 31,8\% dos trabalhos apresentados nas Reuniões da ANPED Nacional, organizados por pesquisadores catarinenses, dimensionaram informações e conhecimentos acerca desta temática.

Quadro 5 - Temas examinados nas edições da ANPED Nacional entre os anos de 2000 a 2011

\begin{tabular}{|c|c|l|}
\hline QUANTIDADE & $\%$ & \multicolumn{1}{|c|}{ TEMAS EXAMINADOS NAS EDIÇŌES DA ANPED NACIONAL ${ }^{10}$} \\
\hline 7 & 31,8 & HISTÓRIA DA PROFISSÃO DOCENTE E FORMAÇÃO DE PROFESSORES \\
\hline 5 & 22,7 & HISTORIOGRAFIA E HISTÓRIA DA EDUCAÇÃO BRASILEIRA \\
\hline 5 & 22,7 & NACIONALIZAÇÃO \\
\hline 4 & 18,2 & EDUCAÇÃO \\
\hline 4 & 18,2 & HISTÓRIA DAS INSTITUIÇÕES DO ENSINO PRIMÁRIO \\
\hline 3 & 13,6 & AUTOBIOGRAFIA E MEMÓRIAS \\
\hline
\end{tabular}

9 O Grupo de Trabalho História da Educação (GT02) constituiu-se a partir da proposição em promover a aproximação entre os pesquisadores da área em todo o país, constituindo-se em um espaço de discussão de questões associadas à historiografia da educação.

10 O número da quantidade e da porcentagem diferenciam do total por entrecruzar dois termos para uma mesma publicação. 


\begin{tabular}{|c|c|l|}
\hline 3 & 13,6 & ESTADO/REGIÕES/LOCALIDADE \\
\hline 3 & 13,6 & FONTES E METODOS \\
\hline 3 & 13,6 & HISTÓRIA DA LEITURA E DA ESCRITA \\
\hline 3 & 13,6 & INSTRUÇÃO PÚBLICA \\
\hline 3 & 13,6 & PATRIMŌNIO ESCOLAR/CULTURA MATERIAL ESCOLAR \\
\hline 3 & 13,6 & PESQUISA \\
\hline 2 & 9 & CULTURA ESCOLAR \\
\hline 2 & 9 & HISTÓRIA E INFÂNCIAS \\
\hline 2 & 9 & PEDAGOGIA \\
\hline 2 & 9 & POLİTICAS PÚBLICAS E EDUCACIONAIS \\
\hline 1 & 4,5 & CLASSES SOCIAIS \\
\hline 1 & 4,5 & ESTUDOS CULTURAIS \\
\hline 1 & 4,5 & ESTUDOS DA JUVENTUDE \\
\hline 1 & 4,5 & ESTUDOS DE GËNERO \\
\hline 1 & 4,5 & HISTÓRIA E POLITICAS \\
\hline 1 & 4,5 & HISTÓRIA E PRÁTICAS DO ENSINO SUPERIOR \\
\hline 1 & 4,5 & INTELECTUAIS/PERSONAGENS HISTÓRICOS \\
\hline
\end{tabular}

Fonte: Organizado pelas autoras.

Os temas Historiografia e História da Educação Brasileira (22,7\%) e Nacionalização (22,7\%) aparecem em segundo lugar no rol das temáticas pesquisadas seguidas pelo temas Educação (18,2\%) e História das Instituições do Ensino Primário com o mesmo percentual de produções da temática anterior.

Quadro 6 - Períodos Pesquisados nos trabalhos apresentados nas Reuniões Anuais da ANPED Nacional

\begin{tabular}{|lcc|}
\hline PERIODOS PESQUISADOS NOS TRABALHOS DA ANPED NACIONAL & QUANTIDADE & $\%$ \\
\hline IMPÉRIO (1822 - 1889) & 2 & 9 \\
\hline PRIMEIRA REPÚBLICA (1889-1930) & 9 & 41 \\
\hline ESTADO NOVO (1930-1945) & 2 & 9 \\
\hline REDEMOCRATIZAÇÃO (1945-1964) & $\mathbf{1}$ & $\mathbf{4}, 6$ \\
\hline DITADURA CIVIL MILITAR (1964-1985) & $\mathbf{3}$ & $\mathbf{1 3 , 7}$ \\
\hline TEMPO PRESENTE (1985 - 2013) & $\mathbf{1}$ & $\mathbf{1 8 , 1}$ \\
\hline SEM IDENTIFICAÇÃO & & 4,6 \\
\hline
\end{tabular}

Fonte: Organizado pelas autoras.

Os dados referentes aos recortes temporais apresentados nas Reuniões anuais da ANPED Nacional demonstram a permanência das duas tendências temporais aludidas na APED Sul: o maior interesse sobre o final do século XIX e a primeira metade do século $X X$, convivendo com uma expansão a outras demarcações temporais como ao que alude ao tempo presente $18,1 \%$ (4).

\section{OS CONGRESSOS DA SOCIEDADE BRASILEIRA DE HISTÓRIA DA EDUCAÇÃO - CBHE}

Organizados em uma sociedade científica autônoma, os historiadores da educação realizaram em 2000, na cidade do Rio de Janeiro, seu I Congresso Brasileiro de História da Educação (CBHE) ${ }^{11}$. A produção historiográfica catarinense nesta edição contou com três propostas apresentadas. Nos anos posteriores, a produção de trabalhos de pesquisadores catarinenses, nas edições do CBHE dá um

${ }^{11} \mathrm{O}$ Congresso Brasileiro de História da Educação é um evento vinculado à Sociedade Brasileira de História da Educação (SBHE), criada em 1999, e constitui-se em um espaço de apresentação, discussão e divulgação da produção da área. 
salto quantitativo. Vale destacar o salto numérico observado na edição do VI CBHE em 2011, 32 trabalhos cerca de $36,3 \%$ da produção catarinense na última década estão presentes nesta edição, distribuídos nas diferentes categorias de apresentação: comunicações individuais e coordenadas, minicursos.

O quadro abaixo permite visualizar o número de trabalhos apresentados as edições do CBHE.

Quadro 7 - Apresenta a distribuição dos trabalhos apresentados nas Edições dos Congressos da Sociedade Brasileira de História da Educação no período entre 2000 a 2011

\begin{tabular}{|c|c|c|l|}
\hline $\begin{array}{c}\text { Edição do Congresso } \\
\begin{array}{c}\text { Brasileiro de História } \\
\text { da Educação }\end{array}\end{array}$ & $\begin{array}{c}\text { Local sede } \\
\text { do } \\
\text { Congresso }\end{array}$ & $\begin{array}{c}\text { Número de trabalhos de pesquisadores } \\
\text { catarinenses vinculados a história da } \\
\text { educação }\end{array}$ & TEMA DO CONGRESSO \\
\hline I CBHE/ 2000 & UFRJ/RJ & 3 & Educação no Brasil: história e historiografia \\
\hline II CBHE/2002 & Natal/RN & 4 & História e Memória da Educação Brasileira \\
\hline IV CBHE/2004 & PUC/PR & 19 & Os sujeitos da educação na História \\
\hline V CBHE/2006 & Goiânia/GO & 12 & O ensino e a pesquisa em História da Educação \\
\hline VI CBHE/2011 & Aracaju/SE & 18 & $\begin{array}{l}\text { Invenções, Tradições e Escritas da História da } \\
\text { Educação no Brasil }\end{array}$ \\
\hline Total & & 32 & \\
\hline
\end{tabular}

Fonte: Organizado pelas autoras.

O aumento da participação catarinense no VI CBHE pode denotar dois aspectos. Pode ser "um fenômeno de pura atração exercida pelo evento sobre o grande público da Pós-Graduação brasileira, (...), mobilizado pela necessidade de produção bibliográfica [ou], pode representar a expansão da comunidade brasileira de historiadores da educação" (SAVIANI, CARVALHO, VIDAL, ALVES, NETO, 2011 , p. 35). Esta proposição pode ser constatada na produção de outras frentes de trabalho que dimensionam a história da educação em Santa Catarina como: teses, dissertações, periódicos especializados da área e que serão analisados em outras discussões que comporão esta cartografia.

No que tange as temáticas de interesse, apresentadas nas seis edições do CBHE, a História da Profissão Docente e Formação de Professores mantém-se como tema de maior pertinência ao campo da historiografia educacional catarinense, estando presente em $28,4 \%$ dos trabalhos apresentados. No entanto, a distribuição das temáticas apresentadas no próximo quadro permite perceber a formação de um novo quadro de interesses dos pesquisadores catarinenses que, de maneira geral, desloca a lente dos temas tradicionais da pesquisa em História da Educação tais como "Políticas Públicas e Educacionais", "Reformas Educacionais", "História e Política”, "Instrução Pública”, para temas mais próximos de abordagem culturalista.

Quadro 8 - Temas examinados nas edições dos Congressos da Sociedade Brasileira de História da Educação no período entre 2000 a 2011

\begin{tabular}{|c|c|l|}
\hline QUANTIDADE & $\%$ & \multicolumn{1}{|c|}{ TEMAS EXAMINADOS NAS EDIÇÕES DO CBHE12 } \\
\hline 25 & 28,4 & HISTÓRIA DA PROFISSÃO DOCENTE E FORMAÇÃO DE PROFESSORES \\
\hline 20 & 22,7 & CULTURA ESCOLAR \\
\hline 15 & 17 & PATRIMÖNIO ESCOLAR/CULTURA MATERIAL ESCOLAR \\
\hline 14 & 15,9 & HISTÓRIA DAS INSTITUIÇÕES DO ENSINO SECUNDÁRIO \\
\hline 13 & 14,8 & HISTÓRIA DAS INSTITUIÇÕES DO ENSINO PRIMÁRIO \\
\hline 12 & 13,6 & AUTOBIOGRAFIA E MEMÓRIAS \\
\hline 11 & 12,5 & HISTÓRIA DA LEITURA E DA ESCRITA \\
\hline
\end{tabular}

12 O número da quantidade e da porcentagem diferenciam do total por entrecruzar dois termos para uma mesma publicação. 


\begin{tabular}{|c|c|l|}
\hline 10 & 11,3 & INTELECTUAIS/PERSONAGENS HISTÓRICOS \\
\hline 9 & 10,2 & NACIONALIZAÇÃO \\
\hline 8 & 9 & EDUCAÇÃOO \\
\hline 8 & 9 & ESTADO/REGIÕES/LOCALIDADE \\
\hline 8 & 9 & HISTORIOGRAFIA E HISTÓRIA DA EDUCAÇÃO BRASILEIRA \\
\hline 7 & 7,9 & DISCIPLINARIZAÇÃO/MECANISMOS DE PODER \\
\hline 7 & 7,9 & POLITICAS PÚBLICAS E EDUCACIONAIS \\
\hline 5 & 6,8 & HISTÓRIA E PRÁTICAS DO ENSINO SUPERIOR \\
\hline 5 & 5,7 & ESCOLAS \\
\hline 5 & 5,7 & INSTRUÇÃO PÚBLICA \\
\hline 5 & 5,7 & MODERNIZAÇÃO/MODERNIDADE \\
\hline 4 & 5,7 & PERIOODOS HISTÓRICOS \\
\hline 3 & 4,5 & IDENTIDADES ÉTNICAS \\
\hline 3 & 3,4 & EDUCAÇÃO E RELIGIÃO \\
\hline 3 & 3,4 & ESTUDOS CULTURAIS \\
\hline 3 & 3,4 & FONTES E MÉTODOS \\
\hline 3 & 3,4 & PEDAGOGIA \\
\hline 2 & 3,4 & REFORMA EDUCAIONAL \\
\hline 2 & 2,3 & BOURDIEU \\
\hline 2 & 2,3 & CLASSES SOCIAIS \\
\hline 2 & 2,3 & ESCOLA NOVA \\
\hline 1 & 2,3 & HISTÓRIA E INFÂNCIAS \\
\hline 1 & 1,1 & DISCIPLINAS FRONTEIRIÇAS \\
\hline 1 & 1,1 & EDUCAÇÃO PROFISSIONAL \\
\hline 1 & 1,1 & ESTUDOS DE GÊNERO \\
\hline 1 & 1,1 & HISTÓRIA E POLITICAS \\
\hline 1 & 1,1 & PESQUISA \\
\hline & 1,1 & SOCIALIZAÇÃO \\
\hline
\end{tabular}

Fonte: Organizado pelas autoras.

O movimento de discussão e revisão historiográfica no Brasil começa a ganhar visibilidade a partir dos anos 80 do século XX. Essa ação põe em questão os padrões dominantes das categorias de análise vigentes, até então, na História da Educação Brasileira e inicia um deslocamento para outros centros de interesses mais próximos da História Cultural.

Referente a significativa presença da História Cultural na produção historiográfica da educação Libânia Nacif Xavier (2001), afirma que as tendências verificadas (...) indicam a crescente consolidação de um campo disciplinar que se desenvolve no interior do campo pedagógico mas que nitidamente inscreve-se no âmbito da chamada História Cultural" (XAVIER, 2001, p. 219). No entanto, não se pode tomar essa tendência como única, ou a mais importante, se chama atenção para presença de outras perspectivas teórico-metodológicas, nem sempre situada no campo historiográfico. Dentre a produção levantada nas seis edições do CBHE, no período entre 2000 a 2011, é possível perceber outros diálogos teóricos como o que se apresenta no tema Bourdieu (2,3\% dos trabalhos), que se apresenta sob uma abordagem do campo da sociologia da educação.

$\mathrm{Na}$ esteira das aproximações com a História Cultural, destacam-se, ainda, como centros de interesses à escrita da História da Educação em Santa Catarina, os temas Autobiografias/Memória (13,6\%), História da Leitura e da Escrita (12,5\% ).Em se tratando de deslocamentos, chama a atenção o número de trabalhos que se dedicam ao estudo do tema Cultura Escolar $(22,7 \%$ da produção do CBHE). Tais estudos têm possibilitado, na expressão de Dominique Julia (2001), não apenas adentrar a "caixa preta" da sala de aula, mas também, desnaturalizar a escola enquanto instituição, problematizando-a nas suas dimensões históricas, políticas, sociais e culturais. E ainda, discutir de 
forma articulada os outros aspectos que compõem o universo escolar tais como: tempos, espaços, materiais, sujeitos e conhecimentos envolvidos naquilo que se convencionou chamar de processo de escolarização da sociedade brasileira.

Um terceiro eixo de maior incidência da pesquisa catarinense em História da Educação diz respeito aos estudos do Patrimônio Escolar e Cultura Material Escolar (17\%). Os temas que dão visibilidade a História das Instituições de Ensino Primário $(14,8 \%)$ e Secundário $(15,9 \%)$ são temas perscrutados nas edições do CBHE. O tema Historiografia e História da Educação Brasileira representa 9\% da produção científica nestes Congressos.

Quadro 9 - Períodos Pesquisados nos trabalhos apresentados nos Congressos da Sociedade Brasileira de História da Educação no período entre 2000 a 2011

\begin{tabular}{|c|c|c|}
\hline $\begin{array}{l}\text { PERIODOS PESQUISADOS NOS TRABALHOS APRESENTADOS NO } \\
\text { CBHE }\end{array}$ & QUANTIDADE & $\%$ \\
\hline COLÔNIA (1500-1822) & 3 & 3,4 \\
\hline IMPÉRIO (1822 - 1889) & 8 & 9 \\
\hline PRIMEIRA REPÚBLICA (1889 - 1930) & 22 & 25 \\
\hline ESTADO NOVO (1930 - 1945) & 19 & 21,6 \\
\hline REDEMOCRATIZAÇÃO (1945 - 1964) & 22 & 25 \\
\hline DITADURA CIVIL MILITAR (1964 - 1985) & 7 & 8 \\
\hline TEMPO PRESENTE (1985 - 2013) & 3 & 3,4 \\
\hline SEM IDENTIFICACCÃO & 4 & 4,6 \\
\hline
\end{tabular}

Fonte: Organizado pelas autoras.

Ao mover a lente sobre os recortes temporais, identifica-se uma concentração de estudos da historiografia da educação em Santa Catarina sobre o século XX, em especial sobre a primeira metade desse século que, se somado os três períodos, corresponde a 71,6\% (63 trabalhos) da alocação da pesquisa. Tal tendência, contudo, não faz com que somente este período merecesse a atenção dos pesquisadores em Santa Catarina. Há uma dispersão temporal para os períodos anteriores e posteriores.

\section{CONSIDERAÇÕES}

Debruçar-se sobre os caminhos trilhados pela pesquisa em História da Educação em Santa Catarina, no desenho das cartografias que a conformam, não é tarefa simples. Exige fazer escolhas, instituir categorias, elaborar análises, mover a lente. Assim, na finalização deste texto que discorre sobre a presença da pesquisa historiográfica da educação catarinense nos eventos científicos que reúnem a produção da área retomam-se dois pontos apontados já sinalizados no mesmo.

O primeiro diz respeito aos lugares de circulação da produção científica catarinense. Apontados como importantes lugares de disseminação da produção científica da área de História da Educação, os encontros, seminários, congressos, reuniões de trabalhos organizados no eixo nacional e regional, aglutinam gerações de pesquisadores que gravitam entorno de temáticas que intencionam compreender a formação, a configuração do ensino, da educação no país. No entanto, esses lugares, são os lugares-comuns que de acordo com Peter Gay (1990), são verdadeiros. Verdadeiros porque são lugares autorizados pela ciência na fabricação da história, mas não são verdadeiros pela razão geralmente apresentada. São verdadeiros porque fomentam novos questionamentos, novas 
problematizações, novas abordagens que podem prosseguir até o final dos tempos. O segundo referese a demarcação temporal de maior incidência nos trabalhos analisados - o século XX. Apesar do predomínio de pesquisadores aportando suas investigações neste período, motivados de acordo com Alves (1998, p. 196) pela "oferta ao historiador da educação [de uma] maior quantidade e variedade de fontes", é inegável o alargamento dos conhecimentos históricos para os outros períodos.

Por fim, acredita-se que o mapeamento cartográfico ora apresentado, da pesquisa em História da Educação em Santa Catarina, circunscritos aos trabalhos publicados nos anais e cadernos de resumos dos Seminários da ANPED Sul, nas Reuniões anuais da ANPED Nacional e nos Congressos da Sociedade Brasileira de História da Educação, possa auxiliar na percepção de como a História da Educação no Estado vem sendo construída. Todavia como alerta Gay (1990), “ o mapa que nunca precisará de revisões - é irrealizável por principio", fica a deixa para novas cartografias.

\section{REFERÊNCIAS}

ALVES, C. C. Os resumos das comunicações e as possibilidades esboçadas no II Congresso Luso-Brasileiro de História da Educação. In: CATANI, D.; SOUZA, C. P. de (orgs.). Práticas educativas, culturas escolares, profissão docente. São Paulo: Escrituras, 1998.

BASTOS, M. H. C; BENCOSTTA, M. L. A; CUNHA, M. T. S. Uma Cartografia da Pesquisa em História da Educação na Região Sul: Paraná, Santa Catarina e Rio Grande do Sul (1980 - 2000). Pelotas: Seiva, 2004.

GAY, P. O estilo na História. Tradução Denise Bottmann. São Paulo: Companhia das Letras, 1990.

JULIA, D. A Cultura Escolar como Objeto Histórico. Tradução de Gizele de Souza. In: Revista Brasileira de História da Educação. N. 1, SBHE, Campinas, SP: ed. Autores Associados, 2001.

REVEL, J. (Org.). Jogos de Escalas: a experiência da microanálise. Rio de Janeiro:

Fundação Getúlio Vargas Editora, 1998.

SAVIANI, D., CARVALHO, M. M. C., VIDAL, D., ALVES, C., NETO, W. G. Sociedade Brasileira de História da Educação: constituição, organização e realizações. In: Revista Brasileira de História da Educação. v. 11. n.3 (27), p. 13-45, set./dez. 2011.

XAVIER, L. N. Particularidades de um campo disciplinar em consolidação: balanço do I Congresso Brasileiro de História da Educação (RJ/2000). In: Sociedade Brasileira de História da Educação (org.). Educação no Brasil. Campinas, SBHE \& Autores Associados, 2001. 